\title{
Globe
}

Revue internationale d'études québécoises

\section{Laurent Veyssière et Bernard Fonck (dir.), La guerre de Sept Ans en Nouvelle-France, Sillery/Paris, Septentrion/Presses de l’Université Paris-Sorbonne, 2012}

\section{John Dickinson}

Volume 17, numéro 1, 2014

URI : https://id.erudit.org/iderudit/1028642ar

DOI : https://doi.org/10.7202/1028642ar

Aller au sommaire du numéro

Éditeur(s)

Globe, Revue internationale d'études québécoises

ISSN

1481-5869 (imprimé)

1923-8231 (numérique)

Découvrir la revue

Citer ce compte rendu

Dickinson, J. (2014). Compte rendu de [Laurent Veyssière et Bernard Fonck (dir.), La guerre de Sept Ans en Nouvelle-France, Sillery/Paris,

Septentrion/Presses de l'Université Paris-Sorbonne, 2012]. Globe, 17(1),

234-235. https://doi.org/10.7202/1028642ar d'utilisation que vous pouvez consulter en ligne.

https://apropos.erudit.org/fr/usagers/politique-dutilisation/ 


\section{Laurent Veyssière et Bernard Fonck (dir.) La guerre de Sept Ans en Nouvelle-France, Sillery/Paris, Septentrion/Presses de l'Université Paris-Sorbonne, 2012.}

Les commémorations ont le vent en poupe au Canada, surtout celles concernant les faits d'armes qu'affectionne le premier ministre Steven Harper. Cet engouement du gouvernement fédéral draine les financements culturels souvent aux dépens de la recherche fondamentale en histoire. $\mathrm{Ce}$ volume, issu d'un colloque international de 2009, est exemplaire sur ce point. Certes, la guerre de Sept Ans n'a pas livré tous ses secrets, mais ce qui n'est pas déjà connu relève souvent de l'anecdotique et on a du mal à concevoir qu'un livre comportant une vingtaine de contributions puisse apporter des éléments nouveaux à tous les coups.

Comme toutes les publications issues d'actes de colloque, les contributions sont d'une valeur très inégale et, de surcroit, comme il s'agit d'événements très connus avec un nombre relativement restreint de sources importantes, elles comportent de nombreuses redondances. Si certaines sont de véritables articles comportant une recherche originale et des réflexions intéressantes, d'autres ne font que reprendre les interprétations, les données ou les textes déjà publiés ailleurs (Arnaud Balvay sur les forts des Pays d'en Haut et de la Louisiane; Stephen Brumwell sur l'impact mondial, qui reprend les ouvrages de Jonathan R. Dull; Marcel Fournier sur la généalogie des troupes françaises venues combattre en Amérique; Frédéric Guelton qui n'ajoute rien de très neuf sur le contexte français, car trop centré sur les officiers français en Amérique; Laurent Nerich qui parle du système de défense de la Nouvelle-France ; ou Peter MacLeod qui a déjà amplement disserté avec beaucoup de pertinence sur la contribution amérindienne à ce conflit). Il y a des textes qui font un effort pour faire un tour d'horizon convenable, mais qui n'arrivent pas à se démarquer par une approche originale; le choc culturel et le défi de voir la guerre autrement qu'en termes d'honneur qu'évoque Fonck et la carrière de Bougainville retracé par Laurent Veyssière ajoutent peu de nouveau à notre compréhension des personnages et de l'époque. À l'évidence, on a du mal à s'affranchir des canons de l'historiographie traditionnelle quand il s'agit de l'histoire militaire. D'autres ressassent avec plus ou moins de pertinence les faits et les sources connus de longue date et n'apportent rien de nouveau (Luc Lépine sur les stratégies militaires françaises et britanniques, Desmond Morton, mal servi par le traducteur, mais qui 
demeure très traditionaliste dans sa vision des choses et, enfin, Hélène Quimper qui n'arrive pas à dépasser ce qui est bien connu en écrivant sur les batailles de Québec et de Sainte-Foy). En plus, ces contributions négligent des œuvres récentes et remarquables. Outre les travaux de Dull, je pense notamment au livre posthume de Louise Dechêne, Le peuple, l'État et la guerre sous le Régime français, surtout au sujet du mythe de l'efficacité de la milice coloniale.

On y retrouve quand même des essais qui font utilement le tour de certaines questions, notamment ceux de Jean-Pierre Poussou sur les responsabilités de Montcalm et de Wolfe lors de la bataille des plaines d'Abraham, d'Olivier Chaline sur les enjeux géopolitiques de l'affrontement, de Jacques Mathieu sur l'histoire mémorielle ou de François Ternat sur les négociations diplomatiques. Rien de bouleversant, mais des contributions qui font le point et permettent de poser des questions pertinentes.

Enfin, trois contributions offrent des données nouvelles sur des aspects de la guerre - mais sans doute pas ceux qu'espéraient les politiciens conservateurs. René Chartrand nous offre un survol équilibré de la contribution des miliciens. Rénald Lessard propose une analyse du recrutement, de l'origine et de l'acheminement des Volontaires-Étrangers qui tentèrent de défendre Louisbourg et Québec en 1758-1759 et, contre toute attente, Nicholas Westbrook élabore les stratégies adoptées par les gouvernements de la Nouvelle-Angleterre et notamment du Connecticut pour engager des colons néo-anglais à faire la guerre au Canada. Voilà finalement le point le plus négligé de cette grande campagne militaire: la participation de milliers de colons des Treize colonies pour enrayer la menace française que représentait la Nouvelle-France le long du Saint-Laurent. Il est dommage que ce colloque ait concentré ses feux presque uniquement sur le seul volet français de cette "première guerre mondiale» en négligeant les volets britannique et américain.

John Dickinson

Université de Montréal 